\title{
A COMPARISON OF MOOC DEVELOPMENT AND DELIVERY APPROACHES
}

\author{
Neil Smith ${ }^{1}$ \\ n.smith@open.ac.uk helen.caldwell@northampton.ac.uk \\ Mike Richards ${ }^{1}$ \\ m.richards@open.ac.uk
}

${ }^{1}$ Department of Computing and Communications

${ }^{2}$ Department of Education

The Open University

Milton Keynes

MK7 6AA, UK

\author{
University of Northampton \\ Northampton \\ NN2 7AL, UK
}

\begin{abstract}
We present a comparison of two ways of developing and delivering MOOCs. One was developed by the Open University in collaboration with FutureLearn; the other was developed independently by a small team at Northampton University. The different approaches had very different profiles of pedagogic flexibility, cost, development processes, institutional support, and participant numbers. This comparison shows that, even several years after MOOCs came to prominence, there is a range of viable approaches for MOOCs. MOOCs on existing large platforms can reach many thousands of people, but constrain pedagogical choice. Smaller, self-made MOOCs have smaller audiences but can target them more effectively.
\end{abstract}

\section{The range of MOOCs}

The MOOC, the massively online open course, has a long history. The MOOC phenomenon builds on a long history of distance education, but takes it into the modern online world. Large scale interactions systems, using technology developed for social networks and e-commerce, have been repurposed to deliver education at a large scale to many students at once. Some of the largest courses have had over 160,000 students learning concurrently (Hyman, 2012). This potential large reach, and the changes it allows in educational providers, give MOOCs the potential to foster great innovation in education (Sharples et al., 2014).

However, different MOOCs can use the different aspects of "massive" and "online" in different ways. Moving a course online frees it from the constraints of a physical teaching environment, allowing students to participate in the course without being present in the same place as the teaching staff, and often not present at the same time as the teachers. Elements of this have been in present in blended learning (Garrison \& Kanuka, 2004) courses for several years, where learning activities are moved outside the classroom and students are able to study at the time and place of their choosing, using teaching materials provided, often online.

Since the takeoff of MOOCs as a phenomenon in 2012, several companies and universities have started to offer a range of MOOCs. This is in addition to the tools becoming more usable by a wider variety of educators. Together, this increased range of MOOC platforms has led to a wide variety of MOOCs offered to different audiences.

The demand for MOOCs varies widely by size, interest, prior experience, and many other factors. There is therefore a challenge for educators to select the correct pedagogic style of MOOC, and the correct delivery style, to meet the needs of both the educators and the students.

This paper outlines the authors' experiences with developing and delivering MOOCs for two very different audiences, with different requirements, and delivered on very different platforms. One MOOC was on cyber security and was a large-scale course for tens of thousands of non-specialist participants. This MOOC was produced by The Open University in collaboration with FutureLearn, a UK based MOOC delivery company set up with the backing of several UK universities. The other MOOC was on integrating digital tablets (such as iPads) into teaching across a range of subjects and 
contexts. This was a much smaller course for a few hundred participants and was produced entirely in-house by the University of Northampton.

\title{
Comparison of MOOCs
}

As we said above, MOOCs can vary in a number of ways. In this section, we outline some of these variations and indicate some criteria that should be used when selecting the most suitable approach when developing a new MOOC.

\begin{abstract}
Audience
MOOCs vary in both their intended and actual audience. The audience can vary in both size and expertise. For instance, the cyber security MOOC was intended for a large and non-specialist audience, giving them some understanding of risks to individuals and some simple techniques to mitigate them. In contrast, the Teaching with Tablets MOOC was intended for in-service educators (in a school, higher education, or further education context).
\end{abstract}

These different audiences allow MOOC creators to make different assumptions about the interest, commitment, and level of expertise of the participants, and this affects how the MOOC is designed. MOOCs designed for learners with particular skills or in a particular context will necessarily have a smaller potential audience than one for a less particular audience. In addition, the more selective audience could have more commitment to the MOOC; if the learning delivered by the MOOC aligns with their professional or personal interests, they may be more willing to engage in more demanding learning activities over a longer time.

In contrast, MOOCs for a general audience should be carefully designed to reduce barriers to participation for their participants. The "open" nature of the MOOC means that large numbers of people can sign up to MOOCs almost on a whim, but then not engage with the MOOC once it starts or drop out before they have completed all the activities. Drop-out rates of over $90 \%$ are common (Khalil \& Ebner, 2014), particularly on MOOCs for the general public. But even if a MOOC is designed for a large, general audience, it is another matter to enrol that audience on the MOOC. This is a feature where the choice of MOOC delivery platform can have a significant effect.

\section{Pedagogy}

The first MOOCs (Stacey, 2014), now termed cMOOCs, used a social constructivist pedagogy where participants developed a shared understanding of the topic simultaneously with forming a community of practice around the subject, but these MOOCs are sometimes considered too openended and wooly (Nkuyubwatsi, 2013). Other MOOCs, termed xMOOCs, have adopted a much more didactic approach where students read or watch pre-prepared material and complete automatically-marked exercises. Predictably, xMOOCs have sometimes been criticised for being too directive.

There is a range of pedagogic approaches between these two extremes and there is potential to adopt a nuanced design that navigates these poles in a way that is appropriate for the audience and subject (Conole, 2013). Again, the pedagogic approach taken in a MOOC will have a significant on the design of the course.

\section{Platform and services}

Choice of platform is not just a technical decision, as different platforms have different processes embedded within them and can provide different levels of support for MOOC creators. A variety of platforms have grown up for delivering education online. Many MOOCs, especially those delivered by larger providers such as Udacity and EdX, use bespoke MOOC web platforms to host all the content and student interaction, as well as provide the back-end services for student registration, content creation by course authors, and so on. 
Some MOOCs use existing VLE platforms to deliver pre-prepared content, host student-generated content, and provide a forum for discussion. Some MOOCs, such as the Teaching with Tablets MOOC described below, assemble a particular student engagement platform from a range of VLE and social networking platforms used in concert.

Generally, bespoke MOOC platforms are designed for large audiences of general public as learners. They will often have a single, prescribed pedagogic approach, generally a didactic approach with readings, video clips, and automatically marked formative assessment tasks. There will generally be some facility for student interaction through a forum or question-answer tracking system, but these are often limited in flexibility. Because they are designed for the delivery of a MOOC to a large general audience, the delivery platform is designed to make involvement in the course as smooth as possible for the participant.

MOOC platforms provided by large MOOC organisations have other advantages in the support they can provide educators in creating and delivering MOOCs. As our experience with the cyber security MOOC shows, MOOC providers like FutureLearn have a robust process for creating and refining MOOCs, including technical and editorial support for the creation of learning content. They also tend to have an established base of learners and good publicity mechanisms. This allows the providers to gather large audiences of learners to MOOCs, allowing courses to fulfil the promise of "massive" in their titles.

However, the use of these platforms comes with a cost of reducing the pedagogic flexiblity allowed to the MOOC authors. Large MOOC platforms are designed to cater to the lowest common denominator with a didactic approach. Other pedagogic approaches are not supported and may indeed be impossible within the constraints of the MOOC platform. If the pedagogic requirements of the MOOC require an approach different from what the MOOC platform provides, going elsewhere may be mandatory.

\section{Cyber security: a FutureLearn based MOOC}

The Open University (OU) is the UK's largest university. It offers a range of qualifications from introductory certificates to bachelor's and postgraduate degrees. The OU was founded in 1969 by royal charter with a mission to increase access to higher education. The OU invests heavily in a socalled 'journey from informal to formal learning' by developing learning resources that can be used by casual learners, including television and radio programming as well as educational material on the OpenLearn platform, iTunes U and YouTube. These materials are designed to encourage users to begin using small resource before moving on to free self-study courses and MOOCs and eventually to begin formal study towards a university degree.

FutureLearm was founded in 2012 as the first UK-led MOOC platform. It is wholly owned by the Open University, but operates as a separate company with its own staff and resources. FutureLearn currently has 40 partners from the UK, Europe, Africa, Asia and the Middle East. Partners include universities and other learning institutions as well as archival bodies such as museums and national libraries.

\section{Motivation and context}

Governments and businesses are gradually becoming aware of the vulnerability of computer networks. Individual awareness of cyber security lags behind that of organisations with many people simply uninformed of the risks from using a computer. Personal threats include vulnerabilities to bullying and extortion by the release of personal information, as well as the destruction of data by means of malicious software or the improper usage of computers. Individuals of all ages and backgrounds are increasingly vulnerable and it is necessary to help them acquire the 
skills to protect themselves from malicious attack as well as accidental damage.

An Introduction to Cyber security is a free MOOC lasting eight weeks that provides information about cyber security to a non-specialist audience. Learners study key aspects of cyber security and take practical steps to improve their own security. Learners perform security audits to discover the strengths and weaknesses of their own computer systems, develop backup strategies, install security software and explore the workings of the Internet as well as discussing topical issues with fellow learners and educators.

The cyber security MOOC was funded as a collaboration between the OU's Faculty of Mathematics, Computing and Technology and the United Kingdom government's National Cyber Security Programme managed by the Department of Business, Innovation and Skills (BIS). It forms a significant part of an overall UK government information strategy on cyber security, such as the cyber streetwise campaign (Furnell \& Moore, 2014). The material was written, reviewed and edited by OU staff and reviewed by UK government officials from BIS, the Ministry of Defence, the Cabinet Office and the GCHQ intelligence agency.

\section{Pedagogy and structure}

The course runs four times a year, with every presentation taking eight weeks. Students must create a FutureLearn account to register on the course and access the course materials. Students can join the course up to four weeks after it starts and continue to study after the scheduled course end date (though they will increasingly lack opportunities to discuss the course material with other learners). The course consists of eight themed weeks of study, with each week intended to take three hours of study by a typical non-expert learner (Figure 1). However, learners are able to adjust their study patterns according to their circumstances, and many take advantage of that flexibility.

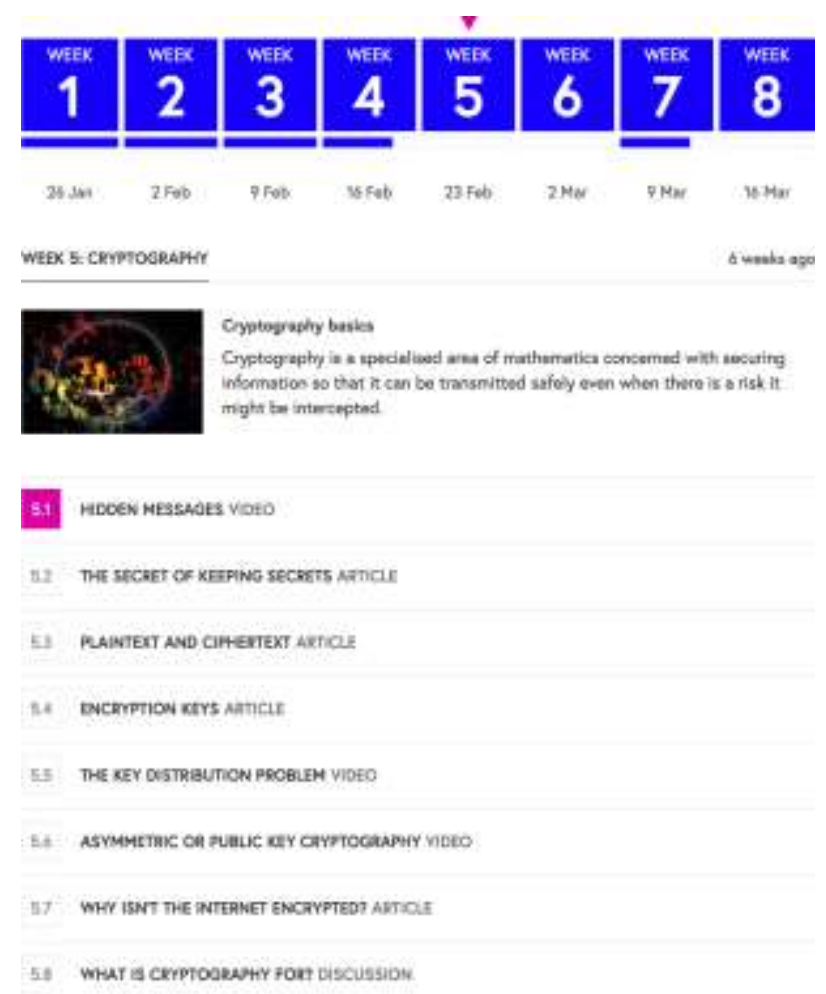

Figure 1. Cyber security course calendar.

The pedagogy of the course is largely dictated by the FutureLearn platform. It is principally a didactic course where students study course-team-prepared material, generally static text and images, supplemented with short animations and video sequences. The material is chunked into small parts within each week; this both increases the flexibility of possible study patterns and 
allows the materials to be easily studied on a variety of devices (PCs, tablets, and phones). The static material is supplemented with exercises and invitations to discuss the course content in the FutureLearn discussion forums. All material is delivered through the one FutureLearn site.

Learners are expected to complete regular activities giving them an opportunity to consolidate their learning and apply their knowledge. The activities give learners an opportunity to practice their new skills in a safe, controlled environment (Whitten \& Tygar, 1999; Sheng et al., 2006), gain experience of new technologies, and realise how useful they are in real use. Completing each of the activities greatly increases the learner's personal security, and collectively, across the cohort, significantly improves the security of the population. The activities include performing a personal cyber security audit, installing various security software packages (antivirus, firewall, and password managers), using public key cryptography.

As learners complete teach study task (reading or activity), they mark it complete on the FutureLearn site.

FutureLearn courses are structured to keep learners within the learning environment as much as possible. Links to materials outside the course are minimised and confined to a Links section on each page rather than being embedded within the text. This is a deliberate decision since linking to other sites not only risks learners being directed to a broken site and being unable to continue their studies, but also risks learners becoming lost in a maze of pages and unable to return to the course. Despite this general FutureLearn philosophy of restricting links, learners on the cyber security MOOC are encouraged to supplement the course materials and follow current cyber security developments by regularly reading relevant news and professional websites. The course team suggests a number of accessible sites including the BBC News, The Guardian, CNet and the Open University's own Safe Computing website.

The course was professionally edited by FutureLearn staff to ensure readability and accessibility for a diverse audience of non-specialist novice readers. Technical language was reduced to the minimum required and a comprehensive glossary of terms was provided for references.

\section{Assessment}

Each week's study has a simple, five-question multiple choice quiz, automatically marked as the student takes the test. Incorrectly-answered questions direct the learner back to the relevant part of the course materials. There is a separate end of course assessment, which is another automaticallymarked multiple choice quiz.

Learners are not required to pass, or even take, any of the assessment tasks. However, if they complete the majority of the learning steps and pass all the tests, learners have the option of buying a certificate of completion. FutureLearn certificates bear the name of the university offering the MOOC (The Open University in this case) but are not considered a university qualification and do not carry any credit towards any university qualification.

\section{Retrospective}

The course has now been delivered several times and continues to be presented on the FutureLearn platform. Student numbers for the first four presentations are shown in Table 1. In the first year of presentation, over 73,000 learners signed up to the MOOC, 36,000 completed at least one of the learning activities, and almost 12,000 completed the course. This retention rate of $21 \%$ is extremely high for this type of MOOC, where completion rates of 5\%-10\% are more common (Adamopoulos et al., 2013). Unfortunately, we do not have more detailed information about partial completions or learner demographics, as that information is retained by FutureLearn for possible future monetisation. 
Table 1

Cyber Security MOOC Learner Numbers

\begin{tabular}{|l|l|l|l|l|l|l|l|l|l|l|}
\hline & \multicolumn{3}{|l}{ Run 1 } & \multicolumn{2}{l}{ Run 2 } & \multicolumn{2}{l|}{ Run 3 } & \multicolumn{2}{l|}{ Run 4 } & \multicolumn{3}{l|}{ Overall } \\
\hline & Number & $\%$ & Number & $\%$ & Number & $\%$ & Number & $\%$ & Number & $\%$ \\
\hline Joiners & 24330 & & 21006 & & 14798 & & 13175 & & 73309 & \\
\hline Learners & 15606 & $64 \%$ & 12811 & $61 \%$ & 8541 & $58 \%$ & 7695 & $58 \%$ & 54815 & $75 \%$ \\
\hline $\begin{array}{l}\text { Active } \\
\text { Learners }\end{array}$ & 13391 & $86 \%$ & 10539 & $82 \%$ & 6763 & $79 \%$ & 5662 & $74 \%$ & 36355 & $66 \%$ \\
\hline Returners & 8657 & $55 \%$ & 6446 & $50 \%$ & 3834 & $45 \%$ & 3096 & $40 \%$ & 22033 & $40 \%$ \\
\hline $\begin{array}{l}\text { Social } \\
\text { Learners }\end{array}$ & 5496 & $35 \%$ & 4143 & $32 \%$ & 2533 & $30 \%$ & 1960 & $25 \%$ & 14132 & $26 \%$ \\
\hline $\begin{array}{l}\text { Full Part- } \\
\text { icipants }\end{array}$ & 4280 & $27 \%$ & 2873 & $22 \%$ & 1766 & $21 \%$ & 1311 & $17 \%$ & 11743 & $21 \%$ \\
\hline
\end{tabular}

The course materials have been adapted to several other contexts, including presentation in other counties.

By any measure, this MOOC has delivered on its requirements, giving a large number of presumably unskilled members of the public a taste of how to make themselves secure online, and perhaps even taking some simple but effective steps to improve their cyber security at home and work.

The pre-existing MOOC platform allowed the academic staff preparing the MOOC to concentrate on the course content, rather than being distracted by evaluating and selecting different components that could be combined to deliver the course. Similarly, the support of editors and artists meant that the learning material was in some cases of higher quality than the academic course team could produce themselves, while also saving the academic time.

However, there are a number of problematic aspects to the FutureLearn MOOC production. Most significant is the constraint on pedagogy imposed by the platform. FutureLearn MOOCs are designed to be easily accessible to wide populations; this constrains how sophisticated the learners can be assumed to be and limits the demands that can be imposed on them for learning. This means that MOOC learning is necessarily limited in depth and breadth (courses are encouraged to last no more than eight weeks with only a few hours of study per week). In addition, the platform only supports a limited number of activities from which to draw on. Most significant is the restricted functionality of the FutureLearn discussion forums. Different activities have separate and independent forums. Discussions are unthreaded, to ease navigation, but this makes it difficult to follow complex long discussions. In addition, there are limited features for searching and tagging discussions. These features combine to yield discussions that are good at recording quick responses and interactions but militate against more sophisticated and in depth discussions.

Another issue is the relationship between FutureLearn and its partners. While wholly owned by The Open University, FutureLearn is a separate commercial entity that has business relationships with many other universities and organisations. FutureLearn is also seeking ways to monetise its student base and learning analytics. This places pressure on FutureLearn to restrict access to the information it has on students and their behaviour, which in turn limits how much MOOC creators can learn about how their MOOCs are received. 


\section{Teaching with tablets: a Blackboard based MOOC}

Much of the content for this MOOC was drawn from the book Teaching with Tablets (Caldwell \& Bird, 2014) and was intended to allow practising educators to translate current theory into classroom practice. The MOOC was an extension of that idea, with the intent to develop a community of practitioners sharing and learning from each other's practice.

\section{Motivation and context}

This MOOC was initiated by the Education department in the University of Northampton. It had two main aims. One was to develop a vehicle for disseminating and sharing practice for using tablets (such as iPads) in a variety of educational settings, including schools and HEIs, and in a variety of disciplines. The other aim was to develop the Education department's experience with creating and delivering MOOCs, in particular how such MOOCs can create and sustain communities of practice in educational settings.

The use of mobile devices in education is increasing rapidly and is likely to continue to grow (Ally, 2009). However, new technology poses challenges to educators in that it requires new approaches to teaching and learning (Luckin, 2010). To ensure mobile devices enhance learning rather than distract from it, educators need timely guidance on these new approaches. Traditional CPD, based on face-to-face seminars and workshops, can reach only a limited number of educators, whereas a MOOC increases accessibility, giving participants more control over the space, place and pace of their learning.

Much of the course content was hosted on the University of Northampton's Blackboard server. The same system also handled student registration.

\section{Pedagogy and structure}

The MOOC used an innovative, hybridised design that combined features of both $\mathrm{x}$ - and cMOOCs in a 'structured connectivism' approach that sought to harness the acknowledged power of learning in social settings with the power of a structured design. Online synchronous interactions were combined with asynchronous interactions, and participants were be encouraged to collaborate and share examples of their developing practice in an online community space.

With this MOOC, the pedagogy drove the structure and the platform. Existing MOOC platforms, such as the one provided by FutureLearn, were a poor fit to the structured connecitivsm pedagogy of the Teaching with Tablets MOOC. The intent of the MOOC was to develop a community around the MOOC, where participants to bring much of their own experience to the community and share their experiences with their peers. We deliberately included a range of educational contexts as we thought they could be useful to all educators. Tablet-based activities and apps intended for young learners could serve as introductory activities for all ages, while more sophisticated activities aimed at older learners could be adapted, or serve as inspiration, for younger learners.

The MOOC was scheduled to last five weeks, with the course site opening two weeks before the formal course start to allow learners to introduce themselves to the community. We seeded these introductory weeks with simple activities to encourage participants to familiarise themselves with the various apps that would be used often throughout the course.

Each week's study consisted of a reading, two main activities, a number of extension activities, and a twitter chat. The readings and activities were hosted on the University of Northampton's Blackboard service and each week's content was only made available from that week onwards. None of the study was compulsory, though participants were encouraged to engage with the reading and at least one of the main activities. 
Interaction between learners was important, and most activities in the MOOC required learners to create some artefact using one or more tablet apps and share it with other learners. We created a public community on Google+ for these activities, as it allows learners to create links to online artefacts and comment on their own and others'. Twitter chats were compiled with Storify and shared online. All these online activities encouraged learners to share their existing expertise and learn from other participants.

\section{Assessment}

There was no formal assessment on the MOOC, though learners could buy a certificate of completion. Award of the certificate required that student could provide evidence of participation in the MOOC, either by showing participation in the Google+ Community or other evidence of using tablets in their own learning environment.

\section{Retrospective}

The MOOC had 570 students registered, of which 294 accessed the course website and 171 accessed some learning material. The Google+ Community had 248 members. The engagement by week shows a reasonably typical drop-off in participation, though $29 \%$ of active learners engaged in the fifth week of content (Table 2). Figure 2 shows how many learners engaged in at least $\mathrm{n}$ weeks of the MOOC: of the 171 learners, 50 engaged in at least four weeks and 36 engaged in all five weeks of material. Generally, responses to the MOOC were postitive, with many participants saying they found the MOOC useful.

Table 2

Engagement by Week for Teaching With Tablets MOOC

\begin{tabular}{|c|c|c|c|c|}
\hline & & of registered & of engaged & of learners \\
\hline Registered & 570 & & & \\
\hline Engagers & 294 & $52 \%$ & $100 \%$ & \\
\hline Learners & 171 & $30 \%$ & $58 \%$ & $100 \%$ \\
\hline 1. Manipulating media & 162 & $28 \%$ & $55 \%$ & $95 \%$ \\
\hline 2. Visible learning & 86 & $15 \%$ & $29 \%$ & $50 \%$ \\
\hline $\begin{array}{l}\text { 3. Technology } \\
\text { outdoors }\end{array}$ & 68 & $12 \%$ & $23 \%$ & $40 \%$ \\
\hline 4. Digital storytelling & 57 & $10 \%$ & $19 \%$ & $33 \%$ \\
\hline $\begin{array}{l}\text { 5. Talk and } \\
\text { collaboration }\end{array}$ & 49 & $9 \%$ & $17 \%$ & $29 \%$ \\
\hline
\end{tabular}




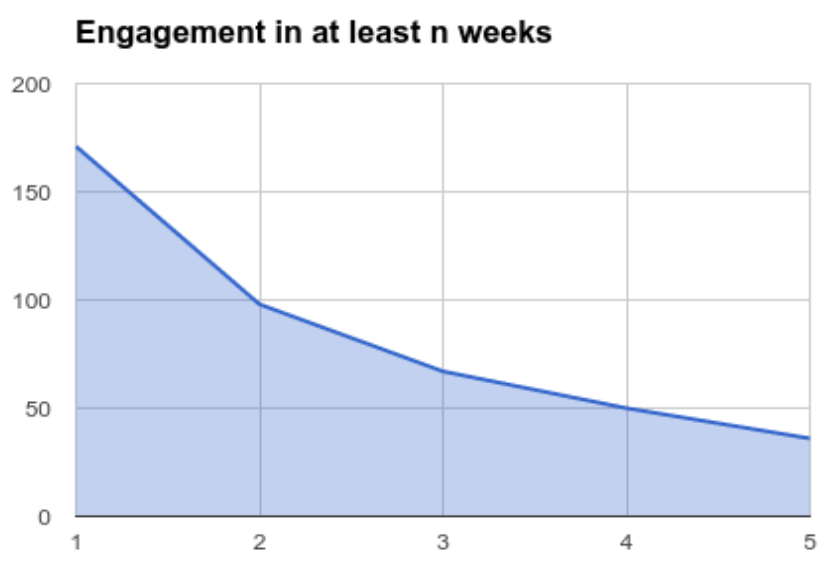

Figure 2. Numbers engaging in at least $\mathrm{n}$ weeks of activity in Teaching with Tablets MOOC.

What is not clear from the numbers is the strength of community that developed from the MOOC. All participants drew examples from their own practice and significant peer learning took place.

\section{Conclusions}

The reviews of the two MOOCs should make the differences clear between the two approaches. The FutureLearn MOOC had the advantage of large reach and support for the academic staff producing the content. However, it had several drawbacks, including a limited choice of pedagogy and constraints on the learning analytics data that was returned to the authors.

In contrast, the Northampton MOOC was much more flexible in its approach, allowing the MOOC to be delivered using a range of tools and platforms to support the most appropriate pedagogy. The details of learners' journeys through the MOOC were more easily captured and analysed, and the staff had a closer relationship with the learners. However, the development of the MOOC required a broader range of skills than with FutureLearn, as the core academic team had to develop all the resources themselves. Finally, the FutureLearn MOOC had a much larger reach than the Northampton one, as FutureLearn was able to publicise the MOOC to its existing base of registered learners. The MOOC had increased reach through the UK government support of the MOOC as part of its cyber security public education efforts.

In conclusion, the correct platform for MOOC development remains open. MOOCs with simple, mainly didactic pedagogies intended for large numbers of learners are best suited on large platforms such as FutureLearn. If the MOOC is intended to serve a more particular audience, or requires a more collaborative pedagogy, such large platforms may not be suitable.

\section{Acknowledgements}

The MOOCs were developed by a large number of staff at The Open University and the University of Northampton. They include Arosha Bandara, Belinda Green, Anna Cox, Jean Edwards, Jim Atkinson, Kim Calvert, Nicki Wise, Robert Farmer, Wayne Chalmers, and Sway Grantham. We thank them all for their valuable contributions.

\section{References}

Ally, M. (2009). Mobile learning: Transforming the delivery of education and training. Athabasca University Press.

Caldwell, H. \& Bird, J. (2015). Teaching with Tablets. London: Sage.

Conole, G. (2013). MOOCs as disruptive technologies: strategies for enhancing the learner experience and quality of MOOCs. Revista de Educación a Distancia, 39, 1-17. 
Furnell, S., Moore, L. (2014) "Security literacy: the missing link in today's online society?." Computer Fraud \& Security 2014.5: 12-18.

Garrison, D. R., Kanuka, H. (2004). Blended learning: Uncovering its transformative potential in higher education. The internet and higher education, 7(2), 95-105.

Hyman, Paul (2012), In the year of disruptive education, Communications of the ACM 55(12) 2022.

Khalil, H. Ebner, M. (2014). MOOCs Completion Rates and Possible Methods to Improve Retention - A Literature Review. In Proceedings of World Conference on Educational Multimedia, Hypermedia and Telecommunications 2014 (pp. 1236-1244). Chesapeake, VA: AACE.

Luckin, R., Clark, W., Garnett, F., Whitworth, A., Akass, J., Cook, J., Robertson, J. (2010). Learner-Generated Contexts: A Framework to Support the Effective. Web 2.0-Based ELearning: Applying Social Informatics for Tertiary Teaching, 70.

Nkuyubwatsi, B. (2013) Evaluation of Massive Open Online Courses (MOOCs) From the Learner's Perspective, Proceedings of the 12th European Conference on e-Learning ECEL-2013, 2, 340346, also available from https://lra.le.ac.uk/handle/2381/28553

Sharples, M., Adams, A., Ferguson, R., Gaved, M., McAndrew, P., Rienties, B., Whitelock, D. (2014). Innovating Pedagogy Milton Keynes: The Open Univeristy.

Sheng, S., Broderick, L., Koranda, C. A., Hyland, J. J. (2006) 'Why johnny still can't encrypt: evaluating the usability of email encryption software', In Symposium On Usable Privacy and Security.

Stacey, P. (2014). The pedagogy of MOOCs. International Journal for Innovation and Quality and in Learning, Issue 3.

Whitten, A. Tygar, J. D. (1999) 'Why Johnny Can’t Encrypt: A Usability Evaluation of PGP 5.0.', In Proceedings of the 8th USENIX Security Symposium, Washington DC, [online] Available from: https://www.usenix.org/legacy/events/sec99/full_papers/whitten/whitten.ps (Accessed 16 April 2015). 